P\&A Año 2, N.2

enero-junio de 2017

pp. 41-56

\title{
Resumen
}

Actualmente la historia de la construcción ha permitido comprender antiguas técnicas de construcción que la aparición de las tecnologías modernas había condenado al olvido. Este esfuerzo ha venido de la mano de la aplicación del método de la lectura dibujada, debido a que gran parte de las fuentes de conocimiento empleadas constituyen tratados y documentos antiguos, cuyo carácter casi críptico plantea ciertas dificultades. La metodología de la lectura dibujada promueve la capacidad del investigador de involucrarse en la época en estudio y a partir de ello explicar gráficamente aquello que los maestros constructores expresaron mediante textos. El presente artículo muestra la aplicación de esta metodología en la interpretación gráfica de los conciertos de obra elaborados por alarifes durante el Virreinato de Perú.

Palabras clave: Construcciones antiguas, dibujo arquitectónico, técnicas constructivas tradicionales.

\section{Lectura dibujada y conciertos de obra. Redescubriendo el método gráfico en la comprensión de técnicas constructivas históricas*}

\author{
Drawn reading and conciertos de obra: Rediscovering the graphic method in the \\ comprehension of historical building techniques \\ Dr. Arq. Pedro Hurtado-Valdez**
}

Recibido: 10 de abril de 2017

Aceptado: 5 de junio de 2017

\begin{abstract}
Currently, the history of building has allowed us to understand past building techniques that have been condemned to oblivion by the emergence of modern technologies. This effort has come hand in hand with the application of the method of "drawn reading", because much of the sources of knowledge used consist of ancient treatises and documents, whose almost cryptic character poses particular difficulties. The methodology of drawn reading furthers the ability of the researcher to get involved in the period under study, from which he graphically explains what master builders expressed through texts. The present article shows the application of this methodology in the graphic interpretation of the notarial records of works elaborated by master builders during the viceroyalty of Peru.
\end{abstract}

Keywords: Ancient buildings, architectural design, historical constructive techniques

* El artículo forma parte de una investigación preliminar sobre técnicas constructivas sismorresistentes. Es una investigación autofinanciada. Se declara no tener conflicto de intereses en la publicación de este artículo.

** Arquitecto por la Universidad Ricardo Palma (URP), doctor arquitecto por la Universidad Politécnica de Madrid, con máster en Restauración de Monumentos (Universidad de Alcalá). Profesor en la URP, y miembro ICOMOS en comités científicos internacionales. Consultor de World Monument Fund (Estados Unidos) 
En tiempos recientes la exploración en el campo de la historia de la construcción ha retomado un renovado vigor, cuyo fruto significó la comprensión de muchas de las antiguas artes edificatorias que el advenimiento de las tecnologías modernas había condenado al olvido. Esta disciplina encontró en la documentación de archivo una fuente inagotable de noticias que le sirven de auxilio para el esclarecimiento de las técnicas constructivas del pasado. Sin embargo, el empleo de tratados y registros antiguos como fuente primaria de conocimiento plantea ciertos retos para su adecuado entendimiento, ya sea por el estilo de escritura o por el lenguaje técnico coloquial con el que los maestros constructores se explayaron en sus textos, al extremo que hoy en día resultan casi crípticos a los ojos de un arquitecto del siglo XXI. Por otro lado, el dibujo como instrumento de la producción arquitectónica ha conseguido traspasar las barreras del tiempo, permitiendo escudriñar y descifrar los procesos edilicios contenidos en los documentos del pasado, de tal forma que el tránsito desde la escritura al medio gráfico desempeña un doble rol, como estímulo del pensamiento abstracto capaz de situarse en una realidad histórica y como eje director para la comprensión de técnicas constructivas tradicionales mediante la búsqueda de los códigos interpretativos correctos.

Tomando las categorías semánticas de Sainz (1990) se puede argumentar que la metodología de la lectura dibujada permite estudiar no solo el lenguaje arquitectónico de las obras edificadas, sino los dos grandes niveles de expresividad del constructor antiguo, el lenguaje gráfico de sus dibujos y el lenguaje verbal empleado en sus textos. Así el medio gráfico aparece como vehículo que brinda una visión apropiada no solo del producto terminado como obra arquitectónica, sino principalmente del proceso y los sustentos técnicos que le dieron origen.

No es intención del presente artículo hacer un examen de todos los medios escritos que pueden ser llevados al dibujo; por el contrario, antes de sumergirse en el mundo de la lectura dibujada es importante hacer una disgregación entre textos de diseño y de cons- trucción. Es decir, no toda la documentación producida en la antigüedad se refiere a técnicas constructivas, sino que en muchos casos se trataba únicamente de mostrar los tipos compositivos de los diferentes estilos arquitectónicos. Por consiguiente, el universo de análisis se circunscribe a las manifestaciones escritas que indican procesos constructivos o explican el comportamiento estructural de la arquitectura histórica.

Para una adecuada comprensión de la metodología de la lectura dibujada se iniciará con un sucinto retrato del estado del arte a partir de sus primeras aproximaciones, principalmente durante el periodo academicista francés en el siglo XIX, hasta palpar el ambiente hispano a partir de los trabajos de Enrique Nuere (2000). Finalmente, esta metodología y su interpretación gráfica serán aplicadas a ejemplos concretos que se asoman en conciertos de obra sobre técnicas particulares desarrolladas en Perú durante el siglo XVII.

\section{El itinerario temporal de la lectura dibujada}

Si bien el dibujo como método de explicación de los sistemas constructivos emergió tempranamente en la historia de la humanidad, su aplicación a la comprensión de documentos antiguos se vio reflejada recién en el Renacimiento, cuando los arquitectos buscaron entender la puesta en obra de las edificaciones grecorromanas. Hasta entonces la explicación de las trazas constructivas se hacía en ambientes casi iniciáticos, motivada por el carácter hermético de la transmisión de los conocimientos de maestro a aprendiz como sujeción a un pasado medieval que organizaba en gremios el trabajo del proyecto y la construcción, la cual perduraría incluso hasta muy entrado el siglo XVIII (ver Figura 1). ${ }^{1}$ El descubrimiento en 1418 de una copia del Manuscrito de Vitruvio en la biblioteca

\footnotetext{
1 En época medieval existieron algunos intentos de pasar de la palabra contenida en un texto al dibujo, como en el Cuaderno de Villard de Honnecourt (1235), pero sin un adecuado acercamiento a los detalles, posiblemente porque se entendía que dichas particularidades podían ser comprendidos inmediatamente por las personas dedicadas a la construcción.
} 
del monasterio de Saint Gallen promovió un enorme entusiasmo por la arquitectura clásica, la cual se enfrentaría prontamente con las primeras dificultades por deducir aquello que el maestro romano expuso en "De Architectura”. Tal dificultad está ejemplificada en la reseña que hace Vitruvio sobre el modo de cubrir ambientes abovedados con madera sin emplear fábrica:

Cuando las circunstancias exijan formar techos abovedados, procédase del siguiente modo: se colocarán unos listones -o pequeñas vigas- rectos que guarden entre sí una distancia no mayor de dos pies[...]Cuando los listones hayan sido fijados formando un arco, se asegurará el entramado o bien el techo abovedado mediante tirantes de madera, y con abundantes clavos de hierro quedaran bien sujetos. Fijados los listones, se sujetarán entre sí mediante una textura de cañas griegas aplastadas, que se atarán con cuerdas de esparto hispano, según lo exija la curvatura de la bóveda. Por la parte superior de este armazón de cañas que forma la bóveda, se extenderá una capa de mortero, de cal y de arena (1995, p. 267)

La traducción gráfica de la bóveda vitruviana no fue materializada sino hasta finales del siglo XVI, momento en que Antonio Rusconi (1590) la interpretó bajo el supuesto de que se trataba de una estructura falsa, y elaboró dos láminas con hipótesis constructivas. Según su deducción la bóveda romana de madera se confeccionaba con tablas de dimensiones variadas, que colgaban de las vigas de un forjado. Bajo ellas se disponían correas longitudinales para ayudar a conferir la curvatura necesaria al tejido de caña que definía finalmente el intradós de la bóveda, todo ello sin el auxilio de camones (ver Figura 2). ${ }^{2}$ Pasaría mucho tiempo hasta que Howe (Vitruvius, 1999), recién en las postrimerías del siglo $\mathrm{XX}$, configurase una imagen axonométrica

2 Los camones son tablas cortas y curvas que sirven para dar forma a las bóvedas encamonadas, que no es el tipo de bóveda descrita por Vitruvio. No obstante, otras traducciones del texto vitruviano mencionan erróneamente las palabras camón para referirse al tejido curvo de caña y encamonado para designar a la bóveda como tal (Vitruvio, 1987 [1787], pp. 171-172; 1986, pp. 176-177), lo cual es evidencia de lo complejo que puede resultar el interpretar textos antiguos sin el auxilio de medios gráficos.

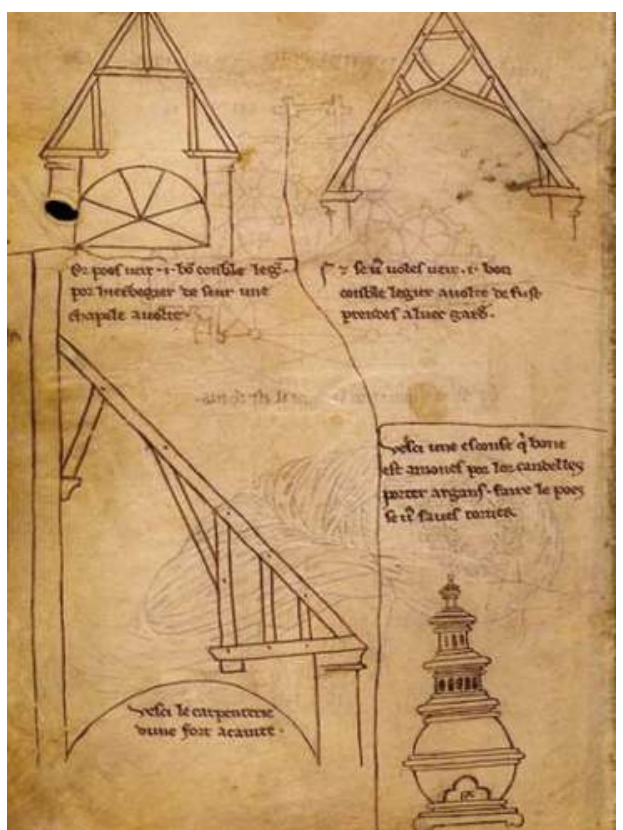

Figura 1. Dibujo con características constructivas de armaduras de cubiertas elaboradas en el Medioevo. En Cuaderno (p. 1235, f. 34), por V. de Honnecourt, 1991, Madrid, España: Akal.

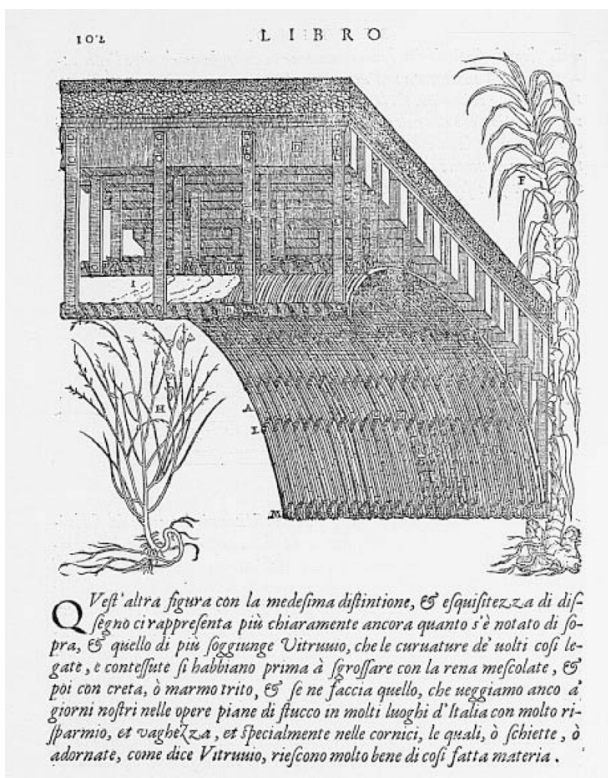

Figura 2. Primera interpretación gráfica de la bóveda de madera descrita por Vitruvio. En Della Architettura, con Centosettanta Figure Disegnate dal Madeimo, Secondo i Precetti di Vitruvio (p. 102), por A. Rusconi, 1590, Venecia, Italia: I. Gioliti. 


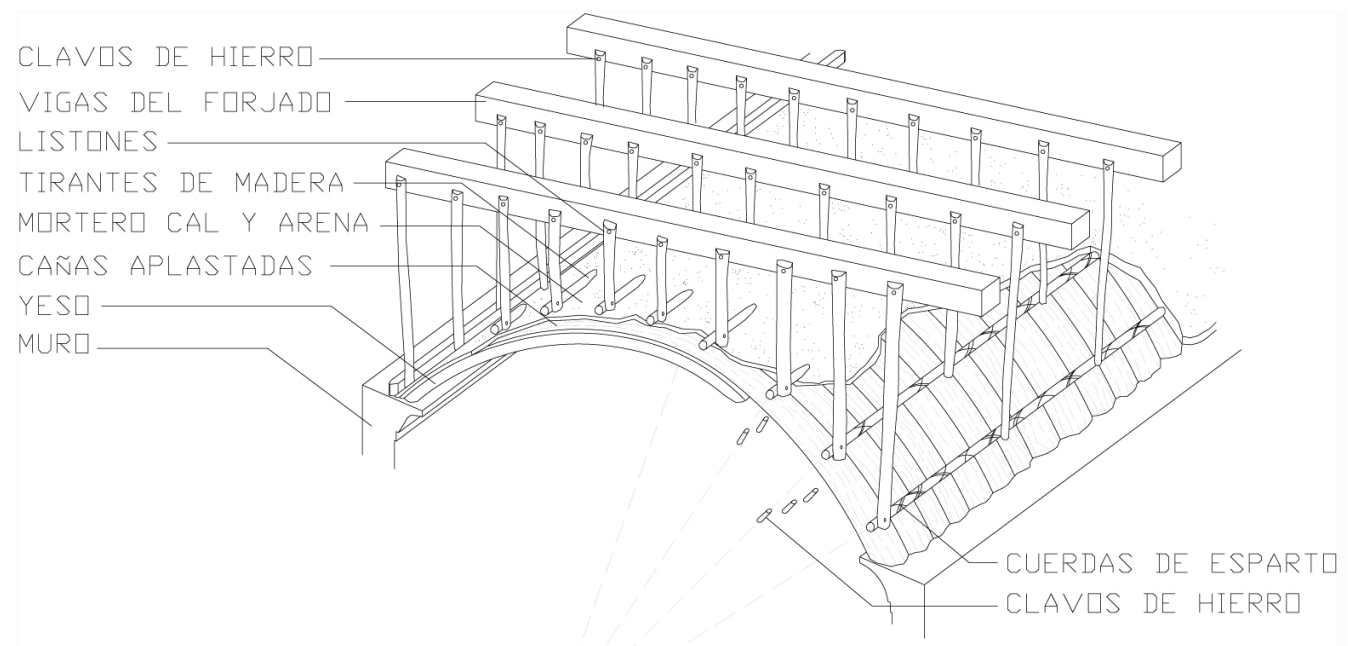

Figura 3. Ejecución de una bóveda de madera descrita por Vitruvio, según la interpretación actual de Howe. Adaptado de Ten Books on Architecture (p. 271), por M. Vitruvius, 1999, Cambridge, Reino Unido: Cambridge University Press.

que brindaba mayor claridad interpretativa a este tipo constructivo (ver Figura 3).

El hecho de que la expresión gráfica durante el Renacimiento fuera considerada por teóricos como Alberti o Zuccari más como un medio de exploración de ideas y proporciones estilísticas que como representación de técnicas edilicias (Sainz, 1990) conspiró contra el estudio de los sistemas constructivos del pasado, en desmedro principalmente de los periodos históricos no clásicos. El vacío en el bosquejo de la construcción antigua se acrecentó por el limitado empleo de los métodos de delineación como apoyo a este tipo de conocimiento, ya que incluso Brunelleschi y Alberti optaron a menudo por maquetas elaboradas en madera y piedra, y muy pocas veces describieron gráficamente un edificio completo (Cerkez, 1999). Así, cuando se empleaba el dibujo para mostrar los sistemas constructivos, estos se centraban mayormente en las novedades del momento y se circunscribían a la exposición de reglas prácticas de construcción confrontadas con la experiencia, empleando el modelo rafaeliano de representación de planta-sección-alzado. ${ }^{3}$

Sin embargo, desde mediados del siglo XVIII, bajo la égida del racionalismo francés y del establecimiento de las bases de la geometría descriptiva por Gaspard Monge en 1798, se pudo codificar los sistemas de representación gráfica en proyecciones ortogonales, perspectivas, axonometrías y proyección oblicua. Surgieron entonces, además de textos que continuaron proponiendo esquemas basados en reglas de proporción, los estudios que buscaban explicar fundadamente el cálculo de las estructuras y determinar la manera más con-

3 Palladio refiere que los puentes, con armaduras parecidas a las cimbras de las bóvedas, seguían reglas de proporciones tradicionales (Palladio, 1570). Igualmente, en 1726 Pitot publicó un artículo titulado "Examen de la Force qu'il Faut Donner aux Cintres Dont on se Sert dans la Construction des Grandes Voutes, des Arches des Ponts...", donde intenta dar una base teórica al cálculo de los elementos que componen las cimbras, indicando que el progreso de la carpintería se había apoyado en una serie de reglas perfeccionadas por la práctica y no en principios teóricos (López Manzanares, 1996). 
veniente para construir en cuanto al ahorro de material y la facilidad de ejecución (López Manzanares, 1996). Por ejemplo, Boistard (1822) había efectuado una detallada descripción de las cimbras empleadas para edificar puentes, que no era otra cosa que el interés por conocer el mejor modo de construir arcos y bóvedas. Esta actitud se vio reflejada en numerosos tratados de la época, que tomaban al dibujo no solo como un medio de expresión artística, sino como una herramienta científica para organizar una hipótesis de diseño capaz de enfrentarse a su comprobación en la realidad.

En esta línea de acción se configuraron tres vertientes descriptivas que incidieron también en el desarrollo de la representación gráfica de la construcción. La primera constaba en emplear imágenes como soporte del cálculo científico de la infraestructura pública de la época, reflejadas en textos dirigidos a ingenieros, como los dibujos exhibidos en el tratado de Chaix y Chambaret (1850). ${ }^{4}$ La segunda vertiente se manifestó en los manuales de construcción como el de Rondelet (1810), que incorporaban imágenes con la intención de revelar la manera correcta de edificar, dirigidos mayormente a arquitectos y constructores. El tercer tipo lo constituían textos que deseaban explicar el desarrollo de las técnicas constructivas a través de la historia, en muchos casos escritos difusos que no establecían claramente las fronteras de estudio y se dirigían a un lector no necesariamente experto.

Tanto si era un texto de cálculo como si se trataba de un manual de construcción, el método elegido de representación gráfica solía ser la planta y el alzado, con detalles de armaduras y fábricas, mayormente concerniente a la disposición de la cimentación y los apoyos. En algunos casos también se acompañaba con tablas de valores y cálculos que se justificaban por la necesidad de saber las características exactas de las estructuras para proceder a un

4 Durante el siglo XIX aparecieron numerosos textos dirigidos al cálculo de estructuras y de construcción de obras civiles, como consecuencia de la formación de los ingenieros franceses de la École Royal des Ponts et Chaussées desde 1747. cómputo fiable o para poder ejecutarlas materialmente. Sin embargo, cuando se trataba de textos que explicaban las técnicas constructivas en la historia, además de la representación plana se empezó a recurrir al uso de la vista tridimensional. Esta exquisitez en la delineación se entiende por el compromiso asumido en los círculos académicos franceses de acercar el conocimiento al pueblo, de facilitar la comprensión por parte de un público carente del conocimiento del idioma gráfico geométrico, a diferencia de aquellas personas que acostumbraban consultar los libros de cálculo o manuales de construcción, por lo general profesionales e intelectuales.

A mediados del siglo XIX, Eugène Viollet-le -Duc desempeñó un papel significativo en la documentación de las obras del pasado a partir del grafismo de secciones constructivas, según las evidencias que fue desentrañando en los edificios franceses durante su labor

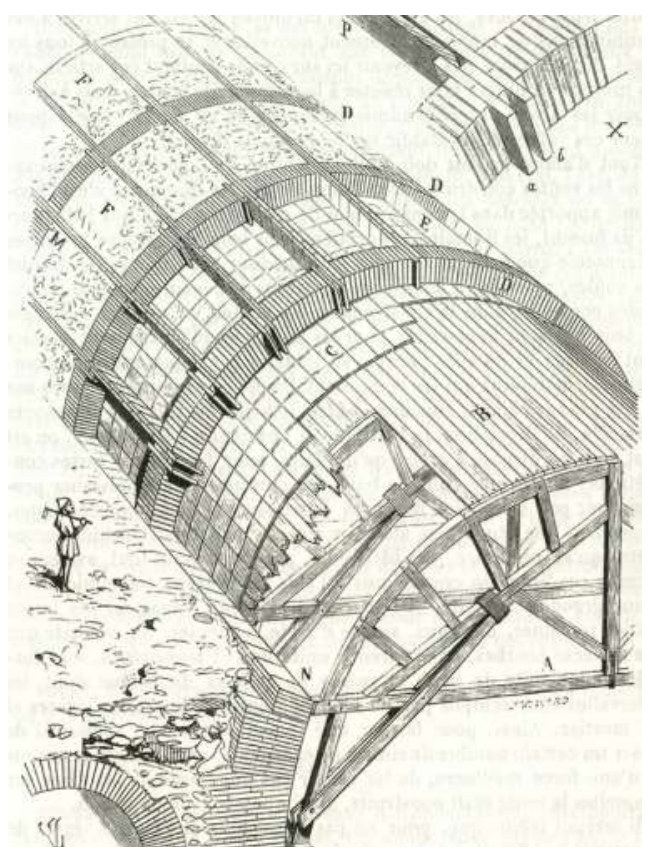

Figura 4. Representación gráfica de la técnica constructiva para levantar bóvedas incluyendo el cimbrado como construcción auxiliar. En Dictionnaire Raisonné de L'Architecture Française. Du XIe au XVIe siécle (vol. 9, p. 475), por E.-E. Viollet-le-Duc, 1868, París, Francia: A. Morel. 
como restaurador de la iglesia de Notre Dame e inspector general del Servicio Diocesano de Francia. La mayoría de las imágenes que desarrolló entre los años 1854 y 1868 fueron publicadas posteriormente en el Dictionnaire Raisonné de L'Architecture Française. Du XIe au XVIe Siécle.

Igualmente, Auguste Choisy en su Histoire de l'Architecture (1970 y 1977 [1899]) no solo indagó en las características constructivas de la arquitectura antigua, sino que también trató de analizarla gráficamente e ilustrar los métodos auxiliares de los que se había servido, actitud que comprobó un marcado interés por los procedimientos y la organización de las obras. Esta situación no fue un hecho aislado, sino que se enmarcaba dentro de la tendencia cultural del espíritu decimonónico, que consideraba importante revelar no solo el corolario de las acciones, sino los procesos que habían llevado a dichos resultados bajo una óptica social de la arquitectura desde la organización del trabajo, de la movilidad de las ideas y del desarrollo de la historia, esta última entendida dentro de las teorías evolucionistas del momento como un ente biológico que mostraba sucesiones de desarrollos, apogeos y decadencias. Tal tendencia marcó la explicación de los métodos constructivos, y motivó el doble rasero valorativo de la arquitectura románica y gótica. En consecuencia, Choisy (1970) delineaba las construcciones del mundo románico utilizando técnicas básicas, mientras que sus apuntes sobre el gótico son más detallados, principalmente por el recurso a las sombras y las texturas, aunque aún se mostraban lejanos a las características gráficas empleadas por Viollet-le-Duc y De Caumont, a los cuales reconoció su aporte en el ámbito del dibujo histórico. ${ }^{5}$

La forma de dibujo de Choisy es la axonometría seccionada, que busca mostrar una

5 Choisy consideró que la arquitectura románica surgió como fruto de la imitación, a diferencia de la arquitectura gótica, que según él era expresión de la originalidad absoluta y de una edad analítica en sumo grado: "el edificio se transforma en un ser organizado donde cada parte constituye un miembro con forma determinada, no ya imitativa de modelos tradicionales..." (1977, p. 401). visión tridimensional sin ningún punto de fuga; propone una interpretación neutra, con una presentación secuencial para explicar el modo de levantar las estructuras. Mientras, De Caumont (1859) y Viollet-le-Duc (1868) utilizaron la sección fugada, lo que condiciona el punto de vista del espectador (ver Figura 4$){ }^{6}$

Posteriores estudios, realizados a finales del siglo XIX y durante el siglo XX, mostraron las numerosas posibilidades que el dibujo podía brindar a la historia de la construcción, aunque esta casi siempre fue tratada como un subproducto del levantamiento de la arquitectura del pasado, y en tanto tal las imágenes que aparecían exponían mayormente edificios completos o parte de ellos más como consecuencia de un proyecto de restauración que de una indagación gráfica desde la documentación histórica.

Enrique Nuere (1985) empezó a aplicar lo que él denominaba lectura dibujada para abordar los manuscritos sobre la carpintería de armar de López de Arenas (1629) y de fray Andrés de San Miguel (1633). Este método le permitió aclarar los pasajes oscuros de estos tratadistas bajo dos premisas, referidas a lo que el dibujo representa (los sistemas constructivos) y lo que desea exponer (la transmisión de los códigos de entendimiento perdidos). Esta reflexión permitió otorgar sentido a cada elemento que aparece en los escritos antiguos y plantear su disposición en la totalidad de la estructura mediante una isometría en fase constructiva, prescindiendo de las partes fáciles de comprender y develando aquellos sectores que de otra forma sería imposible apreciar (Nuere, 2010). Este modo de entender la arquitectura desde los textos sirvió no solo para explicar los sistemas constructivos, sino también para clarificar el proceso de ejecución de los mismos, mediante imágenes que inicialmente se basaron en el empleo del dibujo a mano alzada y otras veces incluían el empleo de herramientas de alarifes como la

6 Ciertamente en el siglo XVI se empleó la isometría caballero, pero sin la intención de explicar los sistemas constructivos antiguos sino aquellos contemporáneos, como se aprecia en la obra de Philibert de L'Orme (1561). 
escuadra y el compás para trasladar medidas, determinar direcciones y definir proporciones (ver Figura 5), con lo cual se demostraba su validez incluso para fijar la traza de una estructura. El posterior empleo de la lectura dibujada ayudó además a dilucidar el funcionamiento de los elementos que conformaban muchas técnicas constructivas a partir de levantamientos de campo (ver Figura 6). Hoy en día los medios digitales, que operan como facilitadores del proceso de dibujo, permiten tener un mayor control del resultado final, pues es posible verificar en las tres dimensiones la pertinencia de la representación espacial y la compatibilidad de las piezas en el conjunto (ver Figura 7).

\section{La terminología antigua y su importancia en la lectura dibujada}

El primer estadio para comprender los textos antiguos se refiere a la metrología empleada en el pasado. Por ejemplo, en el caso del Virreinato de Perú, el sistema de medidas empleado durante el siglo XVII difiere del actual, que es de base decimal, porque en aquellos tiempos se utilizaba el patrón castellano. Es decir, para las fábricas y la carpintería, la longitud y ancho de los muros o de las piezas de madera se establecía en varas y pies, mientras que la escuadría estaba dada en palmos y dedos. Aunque era corriente tener maderos de sección cuadrada con dos palmos de escuadría, a veces se conseguían secciones excepcionalmente grandes, las cuales podían presentarse en varas. ${ }^{7}$

7 El sistema actual de medida en Perú es el métrico decimal, pero en el caso particular de la madera es el pie inglés: 12 pulgadas $(30.48 \mathrm{~cm})$ para la longitud y 1 pulgada $(2.54$ $\mathrm{cm})$ para las escuadrías. Se puede considerar la siguiente equivalencia de medidas principalmente adoptadas:

1 vara castellana $=3$ pies castellanos $=4$ palmos $=48$ dedos $=83.59 \mathrm{~cm}$

1 tercia $=$ tercera parte de una vara $=1$ pie castellano $=16$ dedos $=27.86 \mathrm{~cm}$

1 cuarta $=$ cuarta parte de una vara $=1$ palmo $=12$ dedos $=20.90 \mathrm{~cm}$

1 sexma $=$ sexta parte de una vara $=1 / 2$ pie castellano $=8$ dedos $=13.93 \mathrm{~cm}$

Las unidades se expresaban en números exactos y eventualmente, cuando se trataba de especificar una fracción de la unidad, esta siempre venía dada en medios o cuartos.

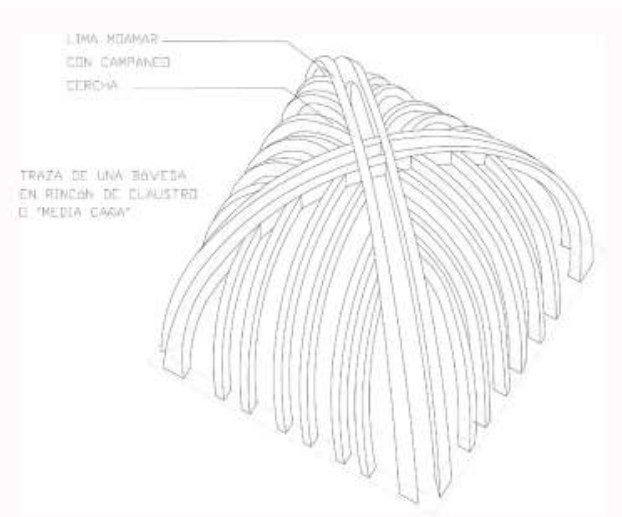

Figura 5. Lectura dibujada de una bóveda de rincón de claustro tipo "media caña" a partir del tratado de San Miguel. Adaptado de La Carpintería de Armar Española, por E. Nuere, 2000, Madrid, España: Munilla-Lería.

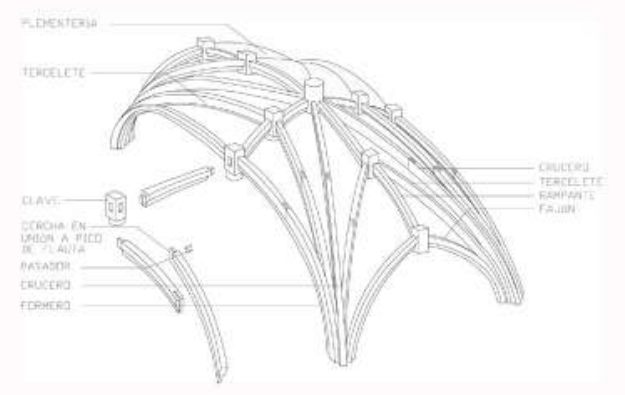

Figura 6. Detalle de la formación de un arco en una bóveda de "costillas" con ensamble a "pico de flauta". Adaptado de Ars Lignea. Las Iglesias de Madera en el País Vasco, por R. Ayerza, J. A. Barrio, J. Gómez \& A. Santana, 1996, Madrid, España: Electa España.

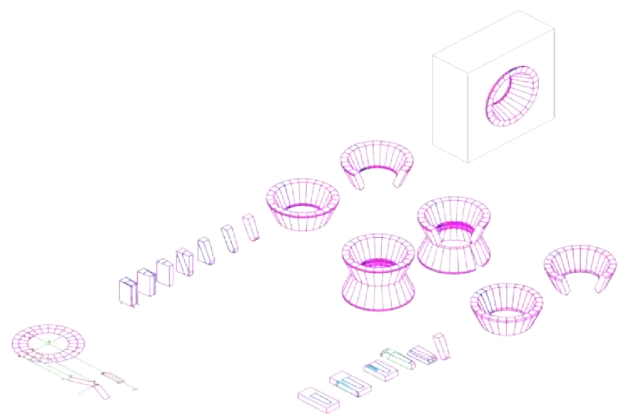

Figura 7. Lectura dibujada del desarrollo de las dovelas de un óculo cónico a partir de su descripción en el tratado de cantería de Gilabert [Dibujo inédito de Hurtado-Valdez]. 


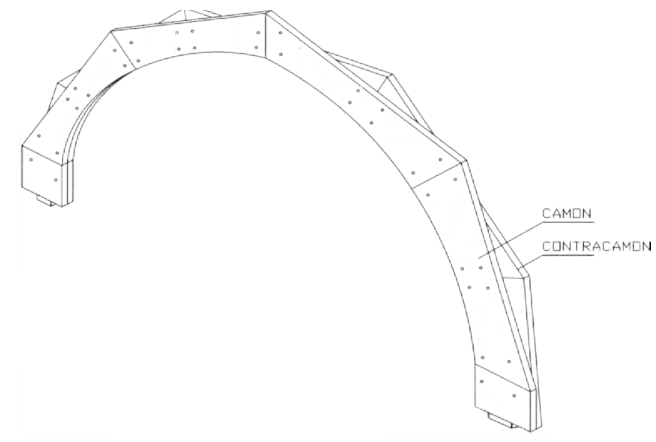

Figura 8. Lectura dibujada de camones y contracamones que conforman una cercha de madera [Dibujo inédito de Hurtado-Valdez].

Un segundo nivel de complejidad constituye la necesidad de entender la caligrafía y el sentido del vocabulario antiguo para la correcta comprensión de los textos, dependiendo de su condición de tratado o de concierto de obra. Muchas veces el lector puede toparse con palabras como contracamones (ver Figura 8) o combadillos, entre otras aún más complejas, que se generaron en la Península Ibérica y atravesaron transformaciones posteriores, consecuencia del desarrollo de la lengua castellana y sus regionalismos en ambas orillas del océano Atlántico (Hurtado Valdez, 2009) ${ }^{8}$. Aquí es de vital importancia realizar un listado de los términos no inteligibles y del contexto en el que fueron formulados para proceder a su análisis paleográfico y decodificación, ensayando dibujos preliminares como primeros indicios de algo que encontrará su lógica más adelante.

En el caso de los tratados, favorece el hecho de que la descripción de las trazas y los sistemas constructivos se acostumbraba acompañar de una imagen, que aunque ciertamente no muy clara, constituye un punto de parti-

8 Los contracamones son piezas curvas de maderas similares a los camones y complementarias a estos en la definición de arcos de madera. Los combadillos son los arcos ornamentales que conforman una bóveda de crucería y se disponen entre arcos estructurales, como los cruceros, terceletes o rampantes. da para su comprensión técnica, a diferencia de los conciertos de obra, que casi siempre se presentan carentes de gráficos. Por ejemplo, si se revisa el texto de López de Arenas, ampliamente conocido tanto en España como en la América del siglo XVII, se encontrará un discurso cuya lectura puede parecer confusa por momentos cuando refiere los diversos aspectos de la construcción con madera. La aplicación de la lectura dibujada a este tratado obliga a elaborar un inventario de los vocablos que es necesario entender y luego realizar una relectura del contenido.

López de Arenas, al narrar al proceso constructivo de una cúpula (media naranja) elaborada con 10 gajos (cascos) formados por arcos de madera, se valía de dos construcciones geométricas y del desarrollo de los husos de la cúpula. Explicaba que el perfil de una media naranja se ejecutaba a partir de la luz libre a salvar, donde la mitad de esta longitud constituía el radio base para la conformación del semicírculo a trazar. Además, se debía continuar el dibujo del semicírculo una sexta parte del diámetro por debajo de la línea del meridiano para determinar la parte del arco de madera que iba empotrada en el muro (bolsores):

Si la quisieres hazer en diez cascos, la demostraré aquí toda enteramente, por la mucha similitud que tiene con la esfera, sea la quadra y buelta redonda de su estribo A.B.C.D. haz su anchura seis partes la linea que la corta por el centro y de ella básate con una sexta parte, como lo dize E.F. y pon el punto del compas en el centro del quadrado, y punto G. y descrive alrededor una parte de circulo, empeçando en el punto E. y acabando en el punto F. (López de Arenas, 1633, f. 32v-33v)

El ancho del huso en la base se obtenía del desarrollo de la longitud total de la circunferencia (vuelta redonda), dividido en la cantidad de gajos propuestos para la cúpula, que en su caso era 10: "toma en 10 partes la buelta redonda estendida en linea recta, y dalos en la linea recta N.O. de la segunda demostración, que será el asiento de los diez cascos propuestos con sus bolsores" (López de Arenas, 1633 , f. 32v-33v) 